\title{
A STUDY OF THE BLOOD-PRESSURE IN CHILDREN SHOWING ORTHOSTATIC ALBUMINURIA *
}

\author{
MURRAY H. BASS, M.D., AND H. WESSLER, M.D. \\ NEW YORK
}

In a previous communication ${ }^{1}$ we have reported our findings in an examination of the size, shape and rate of the heart in a series of children showing orthostatic albuminuria. The results of this examination revealed certain abnormalities in cardiac function and in the configuration of the heart, as seen with the fluoroscope. As has been previously pointed out, many children who are the subjects of orthostatic albuminuria reveal clinically signs and symptoms of vasomotor instability which naturally lead one to inquire into the condition of the blood-pressure. We have, therefore, made blood-pressure determinations on a number of these children previously examined in regard to their hearts, and here wish briefly to report our findings.

Systolic and diastolic pressures were determined by the auscultatory method introduced by Korotkow, the stethoscope being held over the brachial artery at the elbow. The instrument used was the one devised by Bendick, ${ }^{2}$ the cuff, the same as the one used with the Janeway manometer, being 12 c.c. in width. For the determination of diastolic pressure, that point was taken at which the sound heard over the artery suddenly becomes fainter. This so-called fourth phase has been shown to correspond more accurately to the true diastolic pressure than the point at which all sound disappears. ${ }^{3}$ That the readings by the auscultatory method correspond well with those taken by older but more complicated methods has been proved, ${ }^{4}$ but owing to its comparatively recent introduction, it has been but little used in determinations on children. A short series of blood-pressure readings taken by the auscultatory method has been quite recently published by E. Mueller; but we have used as controls figures which we ourselves obtained in readings taken on a series of normal healthy boys ranging in ages from 10 to 15 years, whom we were enabled to examine through the kindness of Dr. L. B. Rosenthal, to whom we here wish to express our indebtedness.

\footnotetext{
* From the Children's Department of Mount Sinai Hospital Dispensary.

* Submitted for publication August 2, 1913.

1. Bass and Wessler: Heart Size and Heart Function in Children Showing Orthostatic Albuminuria, The ARChrves Int. Med., 1913, xi, 403.

2. Bendick, A. J.: Jour. Am. Med. Assn., 1911, Ivi, 1873.

3. Warfield, L. W.: The ARchives INT. MED., 1912, x, 258.

4. Warfield, L. W.: Interstate Med Jour., 1912, xix, 856; also Goodman, E. H., and Howell, A. A.: Univ. Penn. Med. Bull., 1910-11, xxiii, 469.

5 Mueller, E.: Ztschr. f. Kinderh., 1913. vii, Nos. 3-4.
} 
Owing to the dependence of the albuminuria on the posture of the individual, the blood-pressure readings were taken both in the recumbent and in the upright positions, and as a further test of vasomotor competency readings were taken after a short period of exercise.

The points to be considered then are the following:

1. Do the blood-pressures (systolic, diastolic and pulse-pressures) of children showing orthostatic albuminuria differ in any way from those of normal children?

2. What is the effect of change of posture, recumbent or upright, on systolic, diastolic and pulse-pressure and how do these changes compare with those occurring in the normal child?

3. What is the effect of a short period of exercise (stair-climbing) on the blood-pressures?

4. Is it possible to correlate in any way the findings in the shape, size or rate of the heart before and after exercise with the blood-pressure reactions?

BLOOD-PRESSURE IN THE UPRIGHT POSTURE

Before proceeding to a consideration of our results, it may be well to review briefly the main findings of others in the examination of bloodpressures in normal children. In general, it may be said that both systolic and diastolic pressure increase gradually according to the age of the child. The height and weight of the individual, however, are factors of importance, for in two children of the same age the taller or heavier. one will usually be found to have the higher pressure (Wolfensohn$\left.\mathrm{Kriss}^{\mathbb{B}}\right)$. Pressure also appears to be affected by the general hygienic surroundings, for Eminet ${ }^{7}$ found it higher in children living under good conditions than in those dwelling in poor surroundings. Sex does not appear to influence the pressure in children. All authors are agreed that children show considerable variations in pressure, the same child giving different readings on different days though apparently under identical conditions. Salle found as great a variation as $18 \mathrm{~mm}$. of mercury, but others (Oppenheimer and Bauchwitz ${ }^{9}$ ) assert that $10 \mathrm{~mm}$. should be considered the normal limit of variation, while Mueller found a daily variation of only 2 to $5 \mathrm{~mm}$. Salle further points out that high readings frequently result from nervousness on the part of the children during examination.

In comparing the results obtained by us in children showing ortho. static albuminuria with those obtained in normal children, we have con. sidered it best to use as controls children of corresponding heights rather

6. Wolfensohn-Kriss, P.: Arch. f. Kinderh., 1910, liii, p. 332.

7. Eminet, P. P.: Arch. f. Kinderh, 1907, xlvi, 328.

8. Salle, V.: Jahrb. f. Kinderh., 1911, lxxiii, 273.

9. Oppenheimer and Bauchwitz: Arch. f. Kinderh., 1905, xlii, 415. 
than those of corresponding ages. In Table 1 are tabulated the systolic, diastolic and pulse-pressures of twenty-six children showing orthostatic albuminuria, and in parallel columns the figures for normal children of the same height. The figures for the controls of this series were obtained from the literature and were recorded by means of the palpatory method. This accounts for the fact that the figures for the diastolic pressures in the albuminurics seem abnormally low. As a result of this the pulse-

TABLE 1.-Blood-Pressures in Cases of Orthostatic Albuminuria with Normal Controls for the Corresponding Heighths

\begin{tabular}{|c|c|c|c|c|c|c|c|}
\hline \multicolumn{5}{|c|}{$\begin{array}{l}\text { Orthostatic Albuminurics } \\
\text { Blood-Pressure }\end{array}$} & \multicolumn{3}{|c|}{$\begin{array}{l}\text { Normal Controls* } \\
\text { Blood-Pressure }\end{array}$} \\
\hline $\begin{array}{l}\text { Case } \\
\text { No. }\end{array}$ & $\begin{array}{l}\text { Height } \\
\mathrm{cm} .\end{array}$ & Systolic & Diastolic & $\begin{array}{l}\text { Pulse- } \\
\text { Pressure }\end{array}$ & Systolic & Diastolic & $\begin{array}{l}\text { Pulse- } \\
\text { Pressure }\end{array}$ \\
\hline 1 & 115 & 125 & 65 & 60 & $80-95$ & $70-90$ & $10-25$ \\
\hline 2 & 132 & 103 & 85 & .18 & $85-115$ & $80-105$ & $5-35$ \\
\hline 3 & 121 & 110 & 85 & 25 & $80-110$ & $75-100$ & $5-35$ \\
\hline 4 & 117 & 80 & 60 & 20 & $80-95$ & $70-90$ & $10-25$ \\
\hline 5 & 121 & 112 & 80 & 32 & $80-110$ & $75-100$ & $5 \cdot 35$ \\
\hline 6 & 115 & 105 & 60 & 45 & $80-95$ & $70-90$ & $10-25$ \\
\hline 7 & 112 & 98 & 55 & 43 & $80-95$ & $70-90$ & $10 \cdot 25$ \\
\hline 8 & 132 & 112 & 65 & 47 & $85-115$ & $80-105$ & $5-35$ \\
\hline 9 & 126 & 105 & 65 & 40 & $80-110$ & $75-100$ & $5-35$ \\
\hline 10 & 126 & 92 & 75 & 17 & $80-110$ & $75-100$ & $5 \cdot 35$ \\
\hline 11 & 129 & 85 & 70 & 15 & $80-110$ & $75-100$ & $5-35$ \\
\hline 12 & 131 & 110 & 65 & 45 & $85-115$ & $80-105$ & $5-35$ \\
\hline 13 & 142 & 103 & 70 & 33 & $80-125$ & $75-115$ & 5-50 \\
\hline 14 & 130 & 95 & 70 & 25 & $85-115$ & $80-105$ & $5-35$ \\
\hline 15 & 130 & 130 & 75 & 55 & $85-115$ & $80-105$ & $5-35$ \\
\hline 16 & 133 & 120 & 75 & 45 & $85-115$ & $80-105$ & $5-35$ \\
\hline 17 & 135 & 95 & 70 & 25 & $85-115$ & $80-105$ & $5-35$ \\
\hline 18 & 131 & 105 & 90 & 15 & $85-115$ & $80-105$ & $5-35$ \\
\hline 19 & 137 & 110 & 65 & 45 & $85 \cdot 115$ & $80-105$ & $5-35$ \\
\hline 20 & 128 & 117 & 87 & 30 & $80-110$ & $75-100$ & $5-35$ \\
\hline 21 & 157 & 110 & 85 & 35 & $85-120$ & $85-110$ & $5-35$ \\
\hline 22 & 155 & 107 & 75 & 32 & $85 \cdot 120$ & $85-110$ & $5-35$ \\
\hline 23 & 136 & 90 & 75 & 15 & $85-115$ & $80-105$ & $5-35$ \\
\hline 24 & 140 & 110 & 60 & 50 & $80-125$ & $75-115$ & $5-50$ \\
\hline 25 & 151 & 120 & 90 & 30 & $85-120$ & $85-110$ & $5 \cdot 35$ \\
\hline 26 & 145 & 130 & 95 & 35 & $80-125$ & $75-115$ & $5-50$ \\
\hline
\end{tabular}

* These figures are from the literature and are obtained by the oscillatory and palpatory methods.

pressures of these children are considerably greater than those of the controls. That this is merely the result of a different method of obtaining the readings will be apparent when Tables 2 and 3 are considered, where the pressures in both the albuminurics and control children were taken by the same (auscultatory) method.

The systolic pressures in eighteen of the twenty-six albuminurics fall within the variations found in health. Eight of the cases, however, show 
an increased systolic pressure, varying from 2 to $30 \mathrm{~mm}$. of mercury above the upper limit of the normal figures. A careful reexamination of these eight children, however, failed to show that they differed in any way from the remainder, either in respect to subjective symptoms or in the configuration and size of their hearts. As we pointed out in the previous paper before referred to, we are fairly sure that we have ruled out any cases of nephritis, and therefore do not believe that the increased systolic pressure is due to such disease.

Pulse-pressure varies all the way from 15 to 60 , the average being 33 . A comparison between pulse-pressure and pulse-rate did not show any evidently constant relationship.

We may, therefore, say that our results of pressure readings taken in the upright posture approximate closely to the figures for normal children. We may also add that though the appearance of some of the children - their loss of vasomotor tone, as evidenced by cold, clammy skin, cyanotic hands and their generally visceroptotic habitus - would lead one to expect a subnormal blood-pressure, in not a single instance did we find this to be the case.

The few figures for similar examinations to be found in the literature correspond with the results above stated. Matthes, ${ }^{10}$ who examined twenty-one boys 14 to 17 years of age, all of whom showed "albuminuria of puberty," found normal systolic pressures. Salle, ${ }^{8}$ in a very large number of blood-pressure determinations on various types of children, states that the few who were subject to orthostatic albuminuria did not differ in any way from the healthy ones. Finally, Fischl ${ }^{11}$ is also inclined to deny any great variation from the normal in the bloodpressures of children showing orthostatic albuminuria, though as he suggests, his readings being a little below the normal, this may be looked on as an evidence of vasomotor instability.

\section{BLOOD-PRESSURE ON CHANGE OF POSITION}

In drawing conclusions from the behavior of the blood-pressure consequent on change of position from the recumbent to the upright or vice versa, it should be remembered that different results are obtained when the readings are made immediately after such change, than when some time has been permitted to elapse after the change of position. With this in mind, our readings were not made until an interval of five minutes had elapsed to allow the circulation to adjust itself to the altered static conditions.

In Table 2 are recorded the blood-pressures in both the upright and the recumbent positions. A comparison of the figures shows that the

10. Matthes, M.: Deutsch. Arch. f. klin. Med., 1904-05, 1xxxii, 605.

11. Fischl, R.: Arch. f. Kinderh., 1909, lii, 261. 
following changes have occurred: On standing up the systolic pressure fell in fifteen cases (average $12.5 \mathrm{~mm}$.) ; rose in six cases (average 4 $\mathrm{mm}$.$) ; remained unchanged in five. The diastolic pressure under the$ same conditions fell in eleven cases (average $7 \mathrm{~mm}$.) ; rose in ten cases (average $8.5 \mathrm{~mm}$.) ; remained unchanged in five cases. The pulsepressure fell in twenty-two cases (average $9 \mathrm{~mm}$.) ; rose in two cases (average $9 \mathrm{~mm}$.), and remained unchanged in two cases.

TABLE 2.-Blood-Pressures in Orthostatic Albuminurics in the Recumbent and Upright Positions

\begin{tabular}{|c|c|c|c|c|c|c|c|c|c|}
\hline \multicolumn{4}{|c|}{ Systolic } & \multicolumn{3}{|c|}{ Diastolic } & \multicolumn{3}{|c|}{ Pulse-Pressure } \\
\hline $\begin{array}{l}\text { Case } \\
\text { No. }\end{array}$ & $\begin{array}{l}\text { Lying } \\
\text { Down }\end{array}$ & Standing & Difference & $\begin{array}{l}\text { Lying } \\
\text { Down }\end{array}$ & Standing & Difference & $\begin{array}{l}\text { Lying } \\
\text { Down }\end{array}$ & Standing & Difference \\
\hline 1 & 140 & 125 & -15 & 75 & 65 & $-\mathrm{I} 0$ & 65 & 60 & -5 \\
\hline 2 & 103 & 103 & 0 & 85 & 85 & 0 & 18 & 18 & 0 \\
\hline 3 & 105 & 110 & +5 & 75 & 85 & +10 & 30 & 25 & -5 \\
\hline 4 & 90 & 80 & -10 & 65 & 60 & -5 & 25 & 20 & -5 \\
\hline 5 & 110 & 112 & +2 & 85 & 80 & -5 & 25 & 32 & +7 \\
\hline 6 & 120 & 105 & -15 & 70 & 60 & -10 & 50 & 45 & -5 \\
\hline 7 & 92 & 98 & +6 & 60 & 55 & -5 & 32 & 43 & +11 \\
\hline 8 & 115 & 112 & -3 & 65 & 65 & & 55 & 47 & -8 \\
\hline 9 & 103 & 105 & +2 & 60 & 65 & +5 & 43 & 40 & -3 \\
\hline 10 & 98 & 92 & -6 & 70 & 75 & +5 & 28 & 17 & -11 \\
\hline 11 & 98 & 85 & -13 & 70 & 70 & 0 & 28 & 15 & -13 \\
\hline 12 & 110 & 110 & & 65 & 65 & 0 & 45 & 45 & 0 \\
\hline 13 & 98 & 103 & +8 & 58 & 70 & +12 & 40 & 33 & -7 \\
\hline 14 & 115 & 95 & -20 & 85 & 70 & -15 & 30 & 25 & -5 \\
\hline 15 & 140 & 130 & -10 & 75 & 75 & 0 & 65 & 55 & -10 \\
\hline 16 & 120 & 120 & 0 & 80 & 75 & -5 & 40 & 45 & +5 \\
\hline 17 & 110 & 95 & -15 & 75 & 70 & -5 & 35 & 25 & -10 \\
\hline 18 & 115 & 105 & -10 & 85 & 90 & +5 & 30 & 15 & -15 \\
\hline 19 & 105 & 110 & +5 & 55 & 65 & +10 & 50 & 45 & -5 \\
\hline 20 & 140 & 117 & -23 & 100 & 87 & -13 & 40 & 30 & -10 \\
\hline 21 & 130 & 110 & -20 & 70 & 85 & +15 & 60 & 25 & $-\mathbf{3 5}$ \\
\hline 22 & 123 & 107 & -13 & 80 & 75 & -5 & 43 & 32 & -11 \\
\hline 23 & 100 & 90 & -10 & 77 & 75 & -2 & 23 & 15 & -8 \\
\hline 24 & 112 & 110 & -2 & $\mathbf{5 5}$ & 60 & $+\overline{5}$ & 57 & 50 & -7 \\
\hline 25 & 120 & 120 & $\overline{0}$ & 82 & 90 & +8 & 38 & 30 & -8 \\
\hline 26 & 130 & 130 & 0 & 85 & 95 & +10 & 45 & 35 & -10 \\
\hline
\end{tabular}

It will be seen that in our cases of orthostatic albuminuria there is no constant change in systolic or diastolic pressures on change of position. The pulse-pressure on the other hand with few exceptions was smaller in the upright position.

For a critical consideration of these results it will be necessary to inform ourselves of the data in relation to this subject which are available in the literature. Unfortunately, these disclose no unanimity of opinion, but are rather replete with contradictions. Undoubtedly some of these discrepancies are dependent on the method of blood-pressure determina- 
tion used by individual investigators. This applies especially to diastolic pressures, which, when determined by the oscillatory method, as has been heretofore the case, are subject to wide variation and make deductions based on them of doubtful value.

Friedman ${ }^{12}$ found that in the erect posture the systolic pressure falls. A similar statement occurs in the reports of Shapiro ${ }^{13}$ and Langowoy. ${ }^{14}$ With this, Hensen, ${ }^{15}$ however, is not in accord, as he frequently failed to note such a change in pressure on standing. Waldvoge ${ }^{16}$ considers a drop in systolic pressure on rising as a normal reaction within certain quantitative limits. When such a drop of pressure exceeds $10 \mathrm{~mm}$. of mercury it is considered by him pathologic. Birtch and Inman ${ }^{\mathbf{1 7}}$ conclude that in healthy adults not in active training, the systolic pressure is slightly lower in the upright position, the diastolic pressure at the same time is slightly raised with the result that the pulse-pressure is smaller than in the recumbent position. Dietlen ${ }^{18}$ regards a slight systolic fall on rising as a normal change, a slight rise, however, not being necessarily pathologic. In twenty-five normal persons he found that on change of posture in 22 per cent. the systolic pressure was unchanged; in 22 per cent. it was higher in the upright position; in 56 per cent. it was lower in the upright position. The diastolic pressure was usually increased, on an average $10.5 \mathrm{~mm}$. when the upright posture was assumed. John, ${ }^{19}$ in fifty-two cases, found the pulse-pressure on standing smaller in fortynine and larger in three cases. Quite recently Barach and Marks $^{20}$ have reported a series of cases in which pressure readings were taken on a large number of subjects both in the horizontal and in the upright positions, the experimenters attempting at the same time to eliminate the error caused by muscular exertion in changing from one posture to the other, by placing the subject on a movable platform capable of being tilted either vertically or horizontally. From their findings these authors draw the following conclusions:

When the element of muscular effort has been eliminated change of bodily posture from the erect to the horizontal will cause an increase in the maximum pressure, a decrease in the minimum pressure and an increase in the pulse-pressure. After five minutes in the horizontal posture when the subject is retilted to the erect posture the maximum pressure will diminish, the minimum pressure increase and the pulse-pressure diminish. It will be noted that in both instances the pulse-pressure follows the same trend as the maximum pressure. . . .

12. Friedman: Wien. med. Jahrb., 1882. (Quoted by Dietlen.)

13. Shapiro: Wratsch, 1881. (Quoted by Dietlen.)

14. Langowoy: Deutsch. Arch. f. klin. Med., 1900, lxviii, 268.

15. Hensen: Deutsch. Arch. f. klin. Med., 1900, lxvii, 436.

16. Waldvogel: München. med. Wchnschr., 1908, No. 32.

17. Birtch and Inman: Jour. Am. Med. Assn., 1912, No. 4, 265.

18. Dietlen, H.: Deutsch. Arch. f. klin. Med., 1909, xcvii.

19. John, M.: Deutsch. Arch. f. klin. Med., 1908, xciii.

20. Barach, J. H., and Marks, W. L.: ARCH. INT. MEd., 1913, xi, No. 5, 485. 
Nearly all the subjects of this series respond in the same way. The most notable exception was in the "poor muscular cases." These showed a tendency to reversal of the pressure curve. From the erect to the horizontal caused in more than half the cases a decrease of the maximum pressure and an increase in the minimum pressure.

We may, with certain restrictions, extract the following conclusions from these data:

1. On change of posture, systolic pressure may rise or fall to a slight degree.

2. In the upright posture diastolic pressure is slightly higher than in the recumbent.

3. Pulse-pressure is smaller in the upright posture.

Using the Korotkow method, we have taken pressure readings of twenty-two healthy boys between the ages of 10 and 14 years. The results of this examination may be seen in Table 3 and may be summarized as follows:

table 3.-Influence of Change of Posture on Blood-Pressures of Normal Control Children. Readings by the Auscultatory Method

\begin{tabular}{|c|c|c|c|c|c|c|c|c|c|}
\hline \multicolumn{4}{|c|}{ Systolic } & \multicolumn{3}{|c|}{ Diastolic } & \multicolumn{3}{|c|}{ Pulse-Pressure } \\
\hline $\begin{array}{c}\text { Case } \\
\text { No. }\end{array}$ & $\begin{array}{l}\text { Lying } \\
\text { Down }\end{array}$ & Standing & Difference & $\begin{array}{l}\text { Lying } \\
\text { Down }\end{array}$ & Standing & Difference & $\begin{array}{l}\text { Lying } \\
\text { Down }\end{array}$ & Standing & Difference \\
\hline 1 & 117 & 120 & +3 & 87 & 80 & -7 & 30 & 40 & +10 \\
\hline 2 & 105 & 102 & -3 & 77 & 78 & +1 & 28 & 24 & 14 \\
\hline 3 & 112 & 110 & -2 & 80 & 75 & -5 & 32 & 35 & +3 \\
\hline 4 & 100 & 112 & +12 & 55 & 55 & 0 & 45 & 57 & +12 \\
\hline 5 & 138 & 140 & +2 & 90 & 90 & 0 & 48 & 50 & +2 \\
\hline 6 & 135 & 130 & $-\overline{5}$ & 80 & 70 & -10 & 55 & 60 & +5 \\
\hline 7 & 123 & 123 & & 73 & 73 & & 50 & 50 & 0 \\
\hline 8 & 130 & 120 & -10 & 85 & 75 & -10 & 45 & 45 & 0 \\
\hline 9 & 165 & 175 & +10 & 115 & 110 & -5 & 50 & 65 & +15 \\
\hline 10 & 140 & 130 & -10 & 120 & 95 & -25 & 20 & 35 & +15 \\
\hline 11 & 110 & 112 & $\begin{array}{r}10 \\
+\quad 2\end{array}$ & 82 & 90 & +8 & 28 & 22 & $\div 6$ \\
\hline 12 & 120 & 130 & +10 & 60 & 75 & +15 & 60 & 55 & -5 \\
\hline 13 & 140 & 125 & -15 & 75 & 87 & +12 & 65 & 38 & -27 \\
\hline 14 & 112 & 120 & +8 & 75 & 77 & +2 & 37 & 43 & +6 \\
\hline 15 & 115 & 125 & +10 & 60 & 70 & +10 & 55 & 55 & \\
\hline 16 & 140 & 135 & -5 & 50 & 62 & +12 & 90 & 73 & -17 \\
\hline 17 & 145 & 145 & & 60 & 75 & +15 & 85 & 70 & -15 \\
\hline 18 & 125 & 117 & -8 & 82 & 90 & $\begin{array}{l}+8 \\
+8\end{array}$ & 43 & 27 & -16 \\
\hline 19 & 142 & 145 & +3 & 95 & 85 & +10 & 47 & 60 & +13 \\
\hline 20 & 120 & 115 & -5 & 85 & 90 & +5 & 35 & 25 & -10 \\
\hline 21 & 162 & 142 & -20 & 100 & 100 & 0 & 62 & 42 & -20 \\
\hline 22 & 130 & 125 & -5 & 85 & 80 & -5 & 45 & 45 & 0 \\
\hline
\end{tabular}

In the upright position: Systolic pressure is lower in eleven cases (average $8 \mathrm{~mm} . \mathrm{Hg}$ ) ; is higher in ten cases (average $6.5 \mathrm{~mm} . \mathrm{Hg}$ ); is unchanged in two cases. Diastolic pressure is lower in eight cases 
(average $11 \mathrm{~mm} . \mathrm{Hg}$ ); is higher in eleven cases (average $10 \mathrm{~mm} . \mathrm{Hg}$ ); is unchanged in four cases. Pulse-pressure is smaller in nine cases (average $14 \mathrm{~mm} . \mathrm{Hg}$ ); is larger in eight cases (average $9 \mathrm{~mm} . \mathrm{Hg}$ ); is unchanged in four case.

From these figures it will be seen that in these normal children change of posture resulted in no constant change of the systolic, diastolic or pulse-pressures. Any of these factors may vary in either direction.

If it is assumed for purposes of argument that in orthostatic albuminuria there is some abnormality in the circulation, an assumption that is freely made by most investigators of this condition, one is not unnaturally encouraged to seek in variations in blood-pressure, especially in some alteration in pulse-pressure, some evidence of such an abnormality. Especial impetus was given to this phase of the subject by the work of Erlanger and Hooker. ${ }^{21}$ These authors showed in their case of orthostatic albuminuria that the excretion of albumin followed closely a diminution of pulse-pressure resulting from a change of position from the recumbent to the upright. When by various mechanical means such a drop of pulse-pressure was prevented, excretion of albumin failed to take place. This association of fall of pulse-pressure with excretion of albumin led us to hope that in our cases we might find uniformly a decrease of pulse-pressure on change of position from the recumbent to the upright, or at least some evidence of unusual response to postural conditions. Our results as already given, however, do not show any such marked fall of pulse-pressure on change of position, although the figures are somewhat smaller than the controls.

This subject acquires an added interest from its relation to enteroptosis. A majority of our cases show definite stigmata of this condition, probably of congenital origin or disposition. Its significance lies in the abnormality in circulation and blood-pressure, which is supposed to result from an atonic condition of the abdominal wall. Birtch and Inman, ${ }^{17}$ in cases of visceroptosis with relaxation of the abdominal wall, concluded that on rising, although the systolic pressure may behave in a normal manner, the diastolic pressure either remains unchanged or drops. They attribute this drop of diastolic pressure directly to a loss of support of the splanchnic circulation due to atonic abdominal musculature.

Such a reaction we have failed to find in our cases. Whatever the effects we may attribute to muscular atony in orthostatic albuminuria, it may be affirmed that a definite change of peripheral systolic, diastolic and pulse-pressure is not one of them. The muscular atony, if it has any effect at all in these cases, operates otherwise than by the production of dynamic changes in the peripheral circulation.

21. Erlanger and Hooker: Johns Hopkins Hosp. Rep., 1904. 
In concluding this subject we wish to refer to the statement of Elliott, ${ }^{22}$ that a drop of systolic pressure in rising is pathognomonic of cases of orthostatic albuminuria. It is scarcely necessary to say that such a drop of pressure is a normal phenomenon in many cases; and that on the other hand it does not occur with sufficient regularity to invest it with the dignity of an essential symptom.

\section{BLOOD-PRESSURE AFTER EXERCISE}

In the search for tests of heart efficiency in both organic and functional circulatory disturbances, the response of the circulatory apparatus to bodily exertion has at various times been used as an index of its capabilities. In orthostatic albuminurics, it is true, there is no question of organic heart disorder in the ordinary sense. We have indeed shown in a previous article, ${ }^{1}$ that in many cases the hearts are undersized, abnormal in shape and in some cases have noted what may be regarded as an abnormal response on the part of the heart to increased demands on its energy. Such changes are, however, probably congenital or rather developmental in origin, and their causes lie deeper and are more involved than the ordinary causes of heart disease. It cannot be doubted, however, that functionally the cardiovascular system in these cases is not so efficient as in normal children, in proof of which witness the variety of subjective symptoms of which they so frequently complain, the commonest of which are dyspnea and palpitation occurring even after the slightest bodily exertion.

In attempting to gather some information from the literature on the relationship between blood-pressure and exercise, we are at once confronted with a variety of opinions and numerous contradictory statements. Some; as for example, Stursberg and Schmidt, ${ }^{23}$ believe that an examination of the blood-pressure after exercise is of prognostic significance; for they say that an individual, who, after very slight bodily exercise, shows a very large rise in blood-pressure, will be more easily harmed by excessive exercise than one in whom the pressure does not rise so high. This is especially true of those who show marked irritability of their pressure and their pulse-rates. In the same way Kleissel, ${ }^{24}$ from experiments on soldiers, concludes that neurotic individuals reveal an increase of blood-pressure and pulse-rates after exercise to a degree not shown by normal persons. As opposed to these views are the conclusions of Fantus and Staehelin, ${ }^{\mathbf{2 5}}$ who state that in healthy adults the regulation of the blood-pressure is too complicated for us to draw any conclusions

22. Flliott, A. R.: Interstate Med. Jour., 1911, xviii, 721.

23. Stursberg and Schmidt: München. med. Wchnschr., 1913, No. 4, p. 174.

24. Kleissel, R.: Wien. med. Wchnschr., 1911, No. 28, 1810.

25. Fantus and Staehelin: Ztschr. f. klin. Med., 1910, lxx, 444. 
from the behavior of the maximum and minimum pressures after exercise. Masing, ${ }^{26}$ as the result of pressure readings on numerous subjects, decides that in general the increase in blood-pressure after work is proportional to the work done; when the work is repeated the increase is not so great. The increase after muscular exercise is in proportion to the mental effort employed, and the latter varies with practice. In young individuals pressure remains high and fairly constant during work, whereas in the aged it drops after having attained its maximum. Finaliy, Lowsley, ${ }^{27}$ after conducting a series of very interesting experiments on athletes, taking systolic and diastolic pressure readings immediately and at intervals after exertion, concludes that the pressure reacts differently depending on the grade of the exercise - whether it be moderate, rapid, vigorous, fatiguing or exhausting. He believes that prolonged exercise which causes an increase in the pulse-rate also causes an increase in systolic and diastolic pressures. The systolic shows the greatest rise; hence there is an increase in the pulse-pressure which may be interpreted to mean that the heart-beats are augmented as well as accelerated. He emphasizes, as an important gauge of the circulation, the time taken for the pulse-rate and blood-pressure to return to normal after exercise. It is also of interest to note in this connection that Lowsley found albuminuria in those cases which showed small pulsepressures.

Our method of studying the effect of exercise on the blood-pressure was a follows: The pressures were at first determined in the upright position at rest. The children were then made to run up and down three flights of stairs rapidly. The blood-pressure was then immediately taken again, never longer than one-half minute after cessation of the exercise. The need of this haste in making the second reading lies in the wellknown observation that the pressure falls very rapidly within a few minutes after the exercise. Readings made after such an interval give quite different results.

Summarizing Table 4, in which we have recorded the results of our blood-pressure determinations in children showing albuminuria we find that the systolic pressure rose in eighteen cases, was unchanged in two and fell in one case. The increase in systolic pressure was as high as 35 $\mathrm{mm}$. Hg. The diastolic pressure fell in thirteen cases, was unchanged in one and rose in seven cases. The greatest fall was $15 \mathrm{~mm}$; the greatest rise was $15 \mathrm{~mm}$. The pulse-pressure rose in every case after exercise, the rise varying from 10 to $50 \mathrm{~mm}$.

For comparison, we append in Table 5 the blood-pressure of our normal control children taken before and after exercise. When these and

26. Masing, E.: Deutschr. Arch. f. klin. Med., 1902, lxxiv, 253.

27. Lowsley, O. S.: Am. Jour. Physiol., 1910-11, xxvii, 446. 
TABLE 4.-Blood-Pressures in Orthostatic Albuminurics Before and After Exercise

\begin{tabular}{|c|c|c|c|c|c|c|c|c|c|}
\hline \multicolumn{4}{|c|}{ Systolic } & \multicolumn{3}{|c|}{ Diastolie } & \multicolumn{3}{|c|}{ Pulse-Pressure } \\
\hline $\begin{array}{l}\text { Case } \\
\text { No. }\end{array}$ & $\begin{array}{c}\text { Before } \\
\text { Exercise }\end{array}$ & $\begin{array}{l}\text { After } \\
\text { Exercise }\end{array}$ & Difference & $\begin{array}{c}\text { Before } \\
\text { Exercise }\end{array}$ & $\begin{array}{c}\text { After } \\
\text { Exercise }\end{array}$ & Difference & $\begin{array}{l}\text { Before } \\
\text { Exercise }\end{array}$ & $\begin{array}{c}\text { After } \\
\text { Exercise }\end{array}$ & Difference \\
\hline 1 & 105 & 100 & -5 & 65 & 45 & -20 & 40 & 55 & +15 \\
\hline $\begin{array}{l}1 \\
2\end{array}$ & 103 & 105 & $\begin{array}{r}0 \\
+\quad 2\end{array}$ & 70 & $\begin{array}{l}70 \\
60\end{array}$ & -10 & $\begin{array}{l}40 \\
33\end{array}$ & 45 & $\begin{array}{l}+12 \\
+12\end{array}$ \\
\hline 3 & 92 & 115 & +23 & 75 & 90 & +15 & 17 & 35 & +18 \\
\hline 4 & 130 & 130 & & 95 & 90 & -5 & 35 & 40 & $\begin{array}{r}1 \\
+\quad 5\end{array}$ \\
\hline 5 & 110 & 145 & +35 & 85 & 70 & -15 & 25 & 75 & +50 \\
\hline 6 & 95 & 113 & +18 & 70 & 63 & --7 & 25 & 50 & +25 \\
\hline 7 & 80 & 100 & +20 & 60 & 75 & +15 & 20 & 25 & $\begin{array}{r}+5 \\
+\quad 5\end{array}$ \\
\hline 8 & 112 & 125 & +13 & 80 & 80 & 0 & 32 & 45 & $\begin{array}{r}13 \\
+13\end{array}$ \\
\hline 9 & 105 & 122 & +17 & 60 & 68 & +8 & 45 & 54 & $\begin{array}{r}10 \\
+\quad 9\end{array}$ \\
\hline 10 & 85 & 120 & +35 & 70 & 85 & +15 & 15 & 35 & +20 \\
\hline 11 & 130 & 155 & +25 & 75 & 90 & +15 & 55 & 65 & +10 \\
\hline 12 & 103 & 106 & $\begin{array}{l}+3 \\
+\quad 3\end{array}$ & 85 & 65 & -20 & 18 & 41 & +23 \\
\hline 13 & 90 & 90 & 0 & 75 & 70 & -5 & 15 & 20 & $\begin{array}{r}1 \\
+\quad 5\end{array}$ \\
\hline 14 & 120 & 135 & +15 & 75 & 70 & -5 & 45 & 65 & $\begin{array}{r}T \\
+20\end{array}$ \\
\hline 15 & 110 & 113 & $\begin{array}{r}1 \\
+\quad 3\end{array}$ & 85 & 82 & -3 & 25 & 31 & $\begin{array}{r}+6 \\
+\quad 6\end{array}$ \\
\hline 16 & 95 & 125 & +30 & 70 & $7 \overline{5}$ & +5 & 25 & 50 & +25 \\
\hline 17 & 110 & 120 & +10 & 65 & 67 & +2 & 45 & 53 & $\begin{array}{r}18 \\
+\quad 8\end{array}$ \\
\hline 18 & 98 & 117 & $\begin{array}{r}+19 \\
\end{array}$ & 55 & 50 & -5 & 43 & 67 & +23 \\
\hline 19 & 110 & 115 & +5 & 65 & 60 & -5 & 45 & 55 & +10 \\
\hline 20 & 117 & 125 & +8 & 87 & 85 & -2 & 30 & 40 & +10 \\
\hline 21 & 120 & 155 & +35 & 90 & 85 & $-\overline{5}$ & 30 & 70 & +40 \\
\hline
\end{tabular}

Table 6.-Blood-Pressures in Normal Control Children Before and After Exercise

\begin{tabular}{|c|c|c|c|c|c|c|c|c|c|}
\hline \multicolumn{4}{|c|}{ Systolic } & \multicolumn{3}{|c|}{ Diastolic } & \multicolumn{3}{|c|}{ Pulse-Pressure } \\
\hline $\begin{array}{l}\text { Case } \\
\text { No. }\end{array}$ & $\begin{array}{c}\text { Before } \\
\text { Exercise }\end{array}$ & $\begin{array}{l}\text { After } \\
\text { Exercise }\end{array}$ & Difference & $\begin{array}{c}\text { Before } \\
\text { Exercise }\end{array}$ & $\begin{array}{c}\text { After } \\
\text { Exercise }\end{array}$ & Difference & $\begin{array}{l}\text { Before } \\
\text { Exercise }\end{array}$ & $\begin{array}{c}\text { After } \\
\text { Exercise }\end{array}$ & Difference \\
\hline $\begin{array}{r}1 \\
2 \\
3 \\
4 \\
5 \\
6 \\
7 \\
8 \\
9 \\
10 \\
11 \\
12 \\
13 \\
14 \\
15 \\
16 \\
17 \\
18 \\
19 \\
20 \\
21 \\
22\end{array}$ & $\begin{array}{l}120 \\
102 \\
110 \\
112 \\
140 \\
130 \\
123 \\
120 \\
175 \\
130 \\
112 \\
130 \\
125 \\
120 \\
125 \\
135 \\
145 \\
117 \\
145 \\
115 \\
142 \\
125\end{array}$ & $\begin{array}{l}130 \\
135 \\
127 \\
135 \\
165 \\
160 \\
150 \\
155 \\
175 \\
140 \\
138 \\
150 \\
180 \\
160 \\
180 \\
195 \\
160 \\
160 \\
180 \\
150 \\
185 \\
170\end{array}$ & $\begin{array}{r}+10 \\
+33 \\
+17 \\
+23 \\
+25 \\
+30 \\
+27 \\
+35 \\
0 \\
+10 \\
+26 \\
+20 \\
+55 \\
+40 \\
+55 \\
+60 \\
+15 \\
+43 \\
+35 \\
+35 \\
+43 \\
+45\end{array}$ & $\begin{array}{r}80 \\
78 \\
75 \\
55 \\
90 \\
70 \\
73 \\
75 \\
110 \\
95 \\
90 \\
75 \\
87 \\
77 \\
70 \\
62 \\
75 \\
90 \\
85 \\
90 \\
100 \\
80\end{array}$ & $\begin{array}{r}65 \\
70 \\
\mathbf{6 5} \\
\mathbf{6 5} \\
65 \\
\mathbf{6 0} \\
\mathbf{5 5} \\
90 \\
\mathbf{9 5} \\
\mathbf{7 0} \\
\mathbf{7 5} \\
\mathbf{1 0 0} \\
\mathbf{6 5} \\
\mathbf{7 0} \\
\mathbf{7 0} \\
\mathbf{5 0} \\
82 \\
\mathbf{7 0} \\
\mathbf{1 0 0} \\
\mathbf{9 0} \\
\mathbf{9 0}\end{array}$ & $\begin{array}{r}-15 \\
-8 \\
-10 \\
+10 \\
-25 \\
-10 \\
-18 \\
+15 \\
-15 \\
\ldots 20 \\
-20 \\
0 \\
+13 \\
-12 \\
0 \\
+8 \\
-25 \\
-8 \\
-15 \\
+10 \\
+10 \\
+10\end{array}$ & $\begin{array}{l}40 \\
24 \\
35 \\
57 \\
50 \\
60 \\
50 \\
45 \\
65 \\
35 \\
22 \\
55 \\
38 \\
43 \\
55 \\
73 \\
70 \\
27 \\
60 \\
25 \\
42 \\
45\end{array}$ & $\begin{array}{r}65 \\
65 \\
62 \\
70 \\
100 \\
100 \\
95 \\
65 \\
75 \\
2 \\
68 \\
75 \\
80 \\
95 \\
110 \\
125 \\
110 \\
78 \\
110 \\
50 \\
95 \\
80\end{array}$ & $\begin{array}{l}+25 \\
+41 \\
+27 \\
+13 \\
+50 \\
+40 \\
+45 \\
+20 \\
+10 \\
\because \ldots \\
+46 \\
+20 \\
+42 \\
+52 \\
+55 \\
+52 \\
+40 \\
+51 \\
+50 \\
+25 \\
+53 \\
+35\end{array}$ \\
\hline
\end{tabular}


the orthostatic albuminuria cases are compared, the following points may be noted: Both groups react qualitatively in the same manner; the systolic pressures in the orthostatic cases, however, do not increase as much as do those of the normal cases. The diastolic pressures correspond fairly well in the two series. The pulse-pressure after exercise in the cases of orthostatic albuminuria are much smaller than in the controls (as $17: 44$ ). This diminution is attributable to the difference in systolic pressures.

\section{SUMMARY}

To sum up the result of our investigation we may say that the bloodpressures of children suffering from orthostatic albuminuria differ but little from those of normal children. In spite of the apparent vasomotor insufficiency which many of these children showed, the blood-pressure reactions, both in the upright and recumbent postures and also after exercise, revealed no characteristic anomaly. Nor were we able in any way to correlate the blood-pressure findings with the findings in regard to heart shape and size or pulse-rate. Children with orthostatic albuminuria who showed marked cardiovascular symptoms could not be differentiated by means of blood-pressure tests from the remainder of the group.

'These results are disappointing, for the numerous interesting hypotheses concerning the etiology of orthostatic albuminuria would lead one to suppose that the vasomotor system must be in some manner to blame for the condition, especially in view of the results obtained by Erlanger and Hooker. The relationship of lordosis of the lumbar spine to orthostatic albuminuria has also been brought into connection with an abnormal cardiovascular system, since it has been suggested that only those children react to lordosis by an excretion of albumin in whom the vasomotor system is unable to prevent congestion of the kidney. This hypothesis appears plausible, but it cannot be proved or disproved by an examination of the pressure in the peripheral vessels. All that can be said at present is that the blood-pressure in the brachial artery reacts normally, though whether or not this would apply to the blood-pressure in the renal vessels of the same case, we are unable to state.

41 West Eighty-Third Street-122 West One Hundred and Eighteenth Street. 